\title{
The Current Status of Non-Invasive Assessment of Liver Fibrosis: Real Time Tissue Elastography
}

\author{
Hiroyasu Morikawa and Norifumi Kawada \\ Department of Hepatology, Graduate School of Medicine, Osaka City University, \\ Japan
}

\section{Introduction}

Liver biopsy has long been an important tool for assessing the degree of liver fibrosis. Currently, there are many reports and approaches to evaluate the staging of hepatic fibrosis by using noninvasive imaging methods. The main modalities are based on ultrasonography (US) and magnetic resonance imaging (MRI). Among these techniques, Transient Elastography (TE, Fibroscan) has taken a leading role in the noninvasive assessment of liver stiffness at current clinical medicine in Europe. The principal of TE is simple: TE measures the propagation speed of elastic shear wave within the liver parenchyma. The velocity of the wave propagation correlates directly to tissue stiffness; that is, the harder the tissue is, the faster the shear wave spread.

In this chapter, we introduce a new US-based approach for non-invasive assessment of liver fibrosis using real-time tissue elastography (RTE) that can be performed simultaneously with conventional ultrasound probes during routine US examination. RTE is technically different from TE: echo signals representing tissue strain before and under mild compression are compared and analyzed. RTE was developed in Japan for the visual assessment of tissue elasticity integrated in a sonography machine. The technique is based on the Combined Autocorrelation Method that calculates the relative hardness of tissue rapidly from the degree of tissue distortion and displays this information as a color image [Shiina T, 2002]. The distortion of tissue is transferred to a color-coded image according to its magnitude and superimposed translucently on the conventional B-mode image. Such a simultaneous display of tissue elasticity and B-mode images enables us to evaluate the anatomical correspondence between these modalities. The RTE image is constructed by the amount of displacement of the reflected ultrasound echoes under compression. Although US-based elastography is unable to demonstrate physical elasticity directly, it shows the relative degree of tissue strain when subtle compression is applied. In hard tissue, the amount of displacement of the reflected ultrasound echoes is low, whereas, in soft tissue, the amount of displacement is high because soft tissue can be compressed more than hard tissue.

This technology has already been proved to be diagnostically valuable in detecting space occupying lesions in the breast, prostate, and pancreas. In 2007, Friedrich-Rust applied this technique to measure liver stiffness and reported its usefulness for the detection of significant fibrosis ( $\geqq F 2$, area under the receiver operating characteristic curve; AUC 0.93) in combination with AST to platelet ratio index (APRI). In 2010, we reported that AUC for no significant 
fibrosis (F0-1) was 0.89 and 0.92 in RTE and TE, respectively, and AUC for cirrhosis (F4) was 0.93 and 0.95 in RTE and TE, respectively, in 101 patients with chronic hepatitis C.

We report here an update of the RTE system as a tool for the noninvasive assessment of liver stiffness together with an overview of recent advancement in this area in the literature.

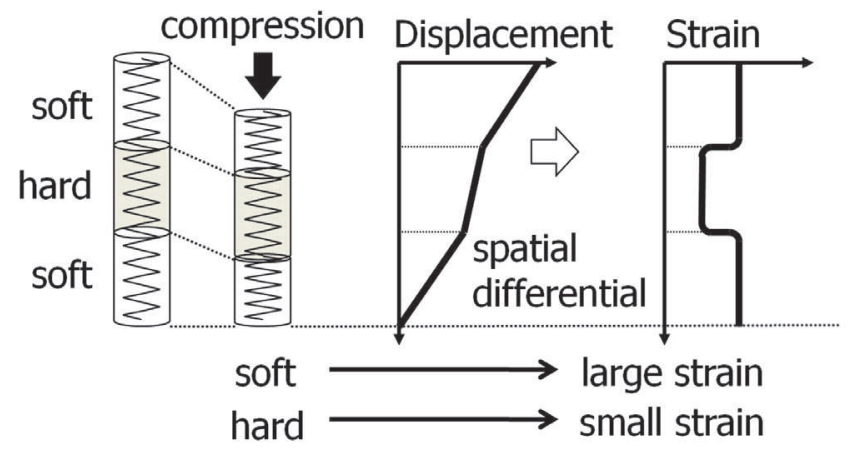

Fig. 1. The principle of real time tissue elastography, illustrated here by a spring model.

\section{Methods}

\subsection{Real-time tissue elastography}

The principle underlining RTE is shown in Figure 1, which indicates a spring model [Ophir J, 1991]. When a spring is compressed, displacement in each section of the spring depends on the stiffness of the spring: a soft spring compresses more than a hard spring. The strain distribution can be measured by spatially differentiating the displacement at each location. Although the tissue displacement is usually generated by manual compression and relaxation of the probe in practice, we were able to improve the acquisition of RTE images representing the distortion of liver tissue as a result of the beating of the heart or pulsing of the abdominal aorta.

RTE is carried out using a high-end model of Hitachi ultrasound system (Hitachi Medical, Chiba, Japan). The developed software with a complex algorithm is able to process all the data coming from the lesion as radiofrequency impulses in a very short time and minimize the artifacts due to lateral dislocations, allowing accurate measurement of the degree of tissue distortion. We used Hitachi EUB-8500 and an EUP-L52 Linear probe (3-7 MHz; Hitachi Medical) for RTE.

This system is currently commercially available for the diagnosis of mammary neoplasm. Patients were examined in a supine position with the right arm elevated above the head, and were instructed to hold their breath. The examination was performed on the right lobe of the liver through the intercostal space, and liver biopsy and Fibroscan were also performed at the same site. The RTE equipment displays two images simultaneously; one shows the regions of interest (ROI) as a colored area and the other indicates the conventional B-mode image (Fig. 2A). We chose an area where the tissue was free from large vessels and near the biopsy point. The measurement was fixed to a rectangle $30 \mathrm{~mm}$ in length and 20 $\mathrm{mm}$ in breadth placed 5-10 $\mathrm{mm}$ below the surface of the liver (Fig. 2A). The color in the ROI was graded from blue (representing hard areas) to red (representing soft areas) (Fig. 2A). We stored the RTE images as moving digital images for 20-40 s. Ten static images captured by the observer at random from the moving images using AVI2JPG v6.10 converter software 
(Novo, Tokyo, Japan) were analyzed using the novel software Elasto_ver 1.5.1,which was developed and donated by Hitachi Medical, on a personal computer. Numerical values of pixels were from 0 to 255 (256 stepwise grading) according to color mapping from blue (0) to red (255), and a histogram of the distribution was generated (Fig. 2B). The scale ranged from red for components with the greatest strain (i.e., softest components) to blue for those with no strain (i.e., hardest components). Green indicated average strain in the ROI, and therefore intact liver tissue was displayed as a diffuse homogeneous green pattern. An appearance of unevenness in the color pattern was considered to reflect a change in the liver stiffness. For quantification, all pixel data in the colored image were transferred into a histogram and binary image (Fig. 2B).

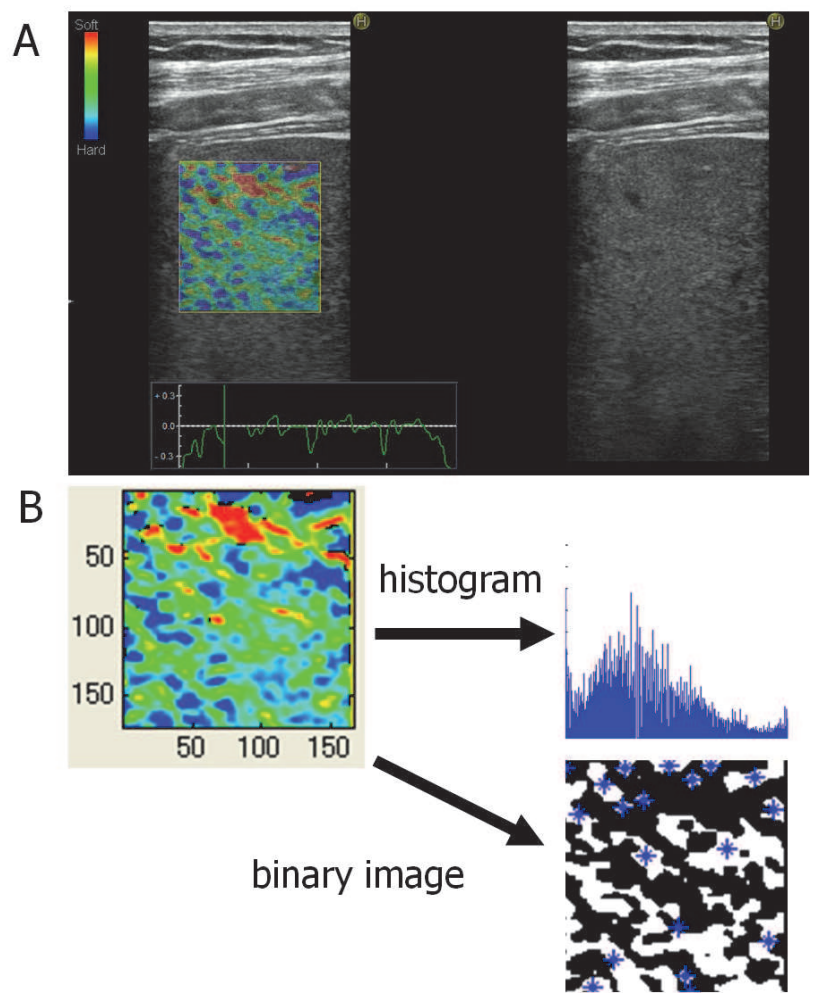

Fig. 2. Procedure of image analyses for real-time tissue elastography.

(A) The ROI was fixed to a rectangle of approximately $20-30 \mathrm{~mm}$ length $\times 20 \mathrm{~mm}$ breadth with a $400-600 \mathrm{~mm}^{2}$ area placed 5-10 $\mathrm{mm}$ below the surface of the liver. Left; RTE image, right; B-mode image. (B) The color-coded images from the ROI of RTE were analyzed by the software Elasto_ver1.5.1. The colors ranged from blue to red indicating the relative gradients from hardness to softness. Mean and Standard deviation were calculated by a histogram, which was generated by 256 stepwise grading derived from the color image. Area and Complexity were calculated from the binary image. Area was derived from the percentage of white regions (asterisks, i.e. hard area). Complexity was calculated as periphery ${ }^{2}$ /Area. Median value of the data were kept as representative of RTE parameters. 
Colored RTE images are usually classified into several patterns in the diagnosis of breast disease. We paid attention to the pattern change of RTE color images according to the progression of fibrosis. We proposed three patterns for representing the stages of liver fibrosis: a diffuse soft pattern, an intermediate pattern, and a patchy hard pattern (Fig. 3). The diffuse soft pattern indicated a homogeneously light-green colored image. The intermediate pattern represented a partially mottled and dotted image with blue spots on a light green background. The patchy hard pattern comprised mixed images with a patchwork effect of light green, red, and blue. Normal or minimally fibrotic liver exhibited a homogeneous RTE image that was colored light green (diffuse soft pattern). According to the progression of liver fibrosis, the homogeneous pattern transitioned to a patchy pattern consisting of a blue-colored area (patchy hard pattern), which may suggest a decrease of homogeneity.

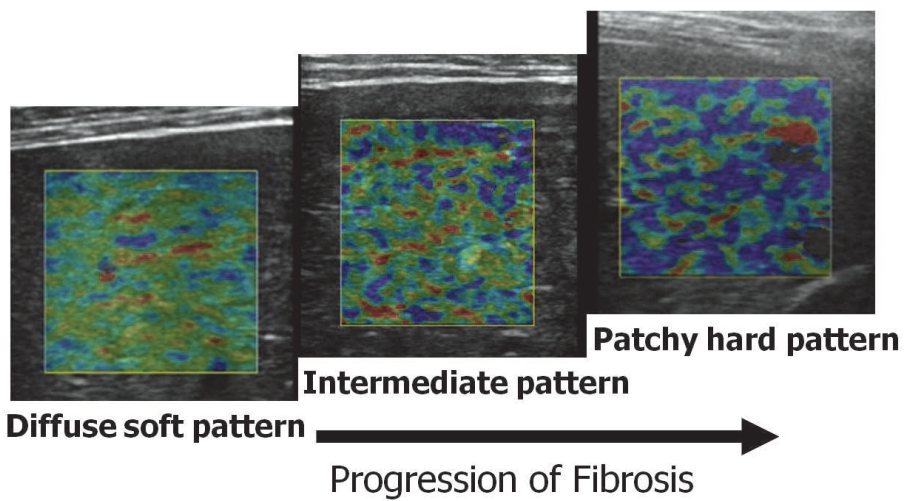

Fig. 3. Representative colored images of real-time tissue elastography according to the progression of liver fibrosis.

Normal or minimally fibrotic liver exhibited a homogenous RTE image that was colored light green. According to the progression of liver fibrosis, the homogenous pattern transitioned to a patchy pattern consisting of a blue-colored area, which may suggest a collapse of homogeneity. A relatively homogeneous light green image indicated a diffuse soft pattern in RTE. A partially mottled and dotted image with blue and red spots in the light green background indicated an intermediate pattern. A mixed image with light green, blue, and red colors indicated patchy hard pattern.

\subsection{Transient elastography}

Liver stiffness was also measured by TE (Fibroscan; Echosens SA, Paris, France). Briefly, patients were placed in a horizontally supine position and a probe was placed on the skin above the right intercostal space. The velocity of shear waves, which were generated temporarily and passed though the liver, was combined with Young's modulus for the automated calculation of elasticity [Yeh WC, 2002]. The measurement depth was between 25 and $65 \mathrm{~mm}$. The results that were obtained in ten valid measurements with a success rate of at least $60 \%$ and an interquartile range under $30 \%$ were considered successful. Failure was defined as when less than ten valid measurements were obtained. A median of 10 valid measurements was regarded as the liver stiffness for a given subject and expressed in kilopascals $(\mathrm{kPa})$. 


\section{Results}

\subsection{Our results}

Our results were expressed as Mean and Standard Deviation (SD), which indicates the mean and the standard deviation of the histogram, respectively. In another analysis, the data were transformed into a binary image and the results were described as Area, which indicates the percentage of hard tissue and represents the hard tissue domain divided by the ROI and Complexity (complex ratio of the shape of an extracted hard tissue domain in the ROI calculated as periphery $2 /$ area of the hard tissue domain). The four image features were calculated automatically by Elasto_ver 1.5.1 (Hitachi Medical). Mean, SD, and Complexity were described in arbitrary units [a.u.].

Figure 4 shows box plots of the RTE values corresponding to fibrosis stage in 126 patients with chronic hepatitis $\mathrm{C}$. The Mean decreased in proportion to the increase of fibrosis score (Jonckheere-Terpstra test, $\mathrm{p}<0.0001$ ). SD, Area, and Complexity increased in proportion to the increase of fibrosis score (Jonckheere-Terpstra test, $\mathrm{p}<0.0001$ ). The significant differences between each fibrosis stage were as follows: F1 versus F3 and F4, and F2 versus F4 for every parameter; F1 versus F2 and F2 versus F3 for Mean; and F3 versus F4 for Complexity (TukeyKramer test, $\mathrm{p}<0.05)$. No significant difference was found between the activity of chronic hepatitis and the fibrosis stages for any parameters (Tukey-Kramer test). The AUC of RTE parameters for no significant fibrosis (F0-1) and cirrhosis (F4) in 121 patients who were also examined successfully by TE, together with the corresponding sensitivities, specificities, and positive and negative predictive values are presented in Table 1.
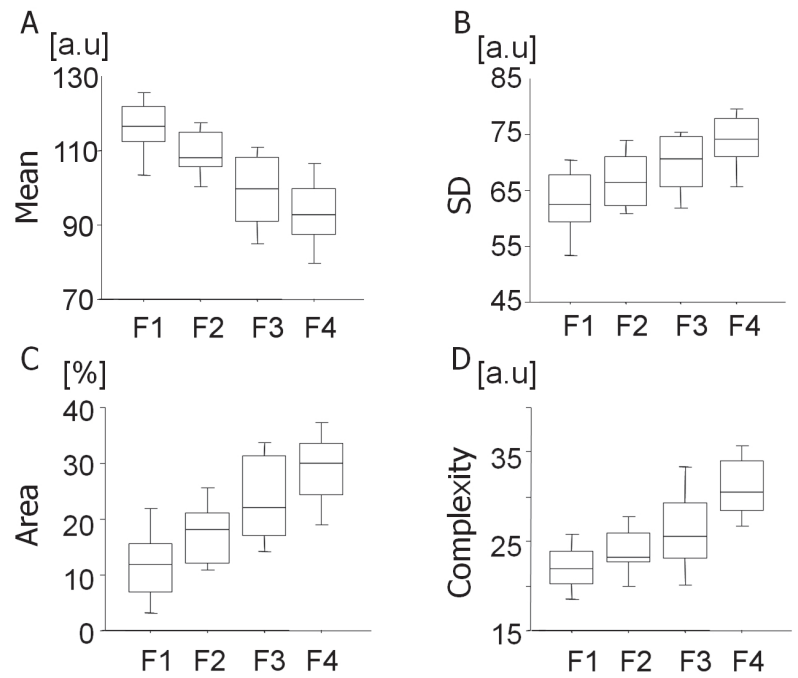

$\mathrm{F} 1, \mathrm{n}=62 . \mathrm{F} 2, \mathrm{n}=19 . \mathrm{F} 3, \mathrm{n}=19 . \mathrm{F} 4, \mathrm{n}=20$. F scale was divided by METAVIR score.

Fig. 4. Parameter analyses measured by real-time tissue elastography for each fibrosis stage. Box plots of each value of RTE corresponding to fibrosis stages F1-4. The top and bottom of the boxes indicate the $1^{\text {st }}$ and $3^{\text {rd }}$ quartiles. The length of the box represents the interquartile range within which $50 \%$ of values are located. The lines through the middle of the boxes represent the median. A) Mean, B) SD, C) Area, and D) Complexity. 


\begin{tabular}{ccccccccccc}
\hline & $\mathrm{F}=0-1$ & \multicolumn{1}{c}{} & \multicolumn{1}{c}{$\mathrm{F}=4$} & & \\
\hline & Mean & SD & Area & Complexity & TE & Mean & SD & Area & Complexity & TE \\
Cut-of & 110.1 & 61.2 & 25.8 & 23.2 & 10.1 & 106.9 & 63 & 29.5 & 24.9 & 13.3 \\
AUC & $\mathbf{0 . 8 9}$ & $\mathbf{0 . 8 1}$ & $\mathbf{0 . 8 7}$ & $\mathbf{0 . 8 1}$ & $\mathbf{0 . 9 2}$ & $\mathbf{0 . 9 1}$ & $\mathbf{0 . 8 4}$ & $\mathbf{0 . 9 1}$ & $\mathbf{0 . 9 3}$ & $\mathbf{0 . 9 5}$ \\
Sensitivity [\%] & 84.1 & 70.5 & 81.8 & 77.3 & 88.6 & 82.8 & 75.9 & 79.3 & 79.3 & 89.7 \\
Specificity [\%] & 82.7 & 73.1 & 80.8 & 75 & 86.5 & 85.1 & 77.6 & 80.6 & 80.6 & 86.6 \\
Accuracy [\%] & 83.3 & 71.9 & 81.3 & 76 & 87.5 & 84.4 & 77.1 & 80.2 & 80.2 & 87.5 \\
\hline
\end{tabular}

TE, transient elastography.

Table 1. Results of comparisons between four image features of real time tissue elastography and transient elastography.

\subsection{Search results}

A PubMed search was conducted in February 2011 for full papers published in journals written in English in the past 5 years. The following keywords were used in combination: "real-time tissue elastography" and "liver". The first author' names, patient's selection critera, patient number, and diagnostic accuracies are summarized in Table 2. The primary outcome was the identification of the degree of fibrosis defined as stages F1 to F4 according to the METAVIR score.

Two articles were reported by Friedrich-Rust in 2007 and 2009, one article was from China, and three articles including ours were from Japan. Three of the articles described studies conducted in patients with chronic liver disease, one article limited the subjects to those with chronic hepatitis B, and two articles including our report included only subjects with chronic hepatitis C. There are two ways to calculate the results of RTE: one is the ratio of strain distribution between the ROI of liver parenchyma and that of other areas, and the other is the analysis of color images in ROI. Koizumi's report showed the best sensitivity and specificity until now; $83.8 \%$ and $90.9 \%$, respectively for $\mathrm{F} 1$, and $90.9 \%$ and $91.5 \%$, respectively, for F4. They used the ratio between the tissue compressibility of the liver parenchyma and that of intrahepatic small vessel. Only two articles Friedrich-Rust's in 2009 and ours in 2010 compared the diagnostic value of RTE with TE. Others compared the value of RTE with serum fibrosis markers represented by APRI.

\section{Discussion}

Liver biopsy has long been the gold standard for the assessment of hepatic fibrosis and will remain important in the diagnosis of liver disease with unknown etiology. However, because of complications, sampling error, and interobserver variability, the role of liver biopsy in the assessment and quantification of fibrosis in viral liver diseases is thought to be less valuable. Many modern noninvasive tests including serum markers and imaging methods are expected to become increasingly important in the near future.

A large number of serum markers have been identified for the assessment of hepatic fibrosis. In clinical practice, type IV collagen $7 \mathrm{~s}$, type III procollagen N-terminal peptide (P-III-P), and hyarulonic acid are commonly utilized as direct serum markers for human liver fibrosis, although it is difficult to distinguish each pathological fibrosis stage using one of these extracellular matrix products. On the other hand, the European Liver Fibrosis (ELF) study reported a marker composed of the combination of P-III-P, hyarulonic acid, and tissue inhibitor of metalloproteinases, which achieved the diagnostic power of AUC 0.80 for Scheuer 3-4 [Guha IN, 2008.]. Reported indirect serum markers of liver fibrosis include AAR (AST/ALT ratio), APRI (AST-to-platelet ratio index), Forns score, FibroTest, and the HALT-C 
model, which are composed of several parameters commonly measured in clinical practice. FibroTest is currently the most carefully evaluated noninvasive serum fibrosis marker panel that is commercially available. FibroTest is an algorithm composed of 6 parameters, including haptoglobin, a2-macroglobulin, apolipoprotein-A1, $\gamma$-glutamyltransferase, bilirubin, and $\gamma$-globulin, and its diagnostic power for $\geqq F 2$ was reported to be AUC 0.87 [Imbert-Bismut F, 2001.]. While the diagnostic accuracy was high, the FibroTest costs more than APRI and the Forns score, and requires two uncommon parameters. In APRI, using the cutoffs proposed by Wai et al. [Wai CT, 2003.], approximately $50 \%$ of patients could be correctly classified as having cirrhosis without a liver biopsy. With the Forns score, the AUC for the prediction of significant fibrosis (Scheuer classification, F2) was 0.86 in the test set and 0.81 in the validation set [Forns X, 2002]. Although direct, indirect, and combined serum marker systems consist of multiple biomarkers, they are all characterized by an AUC for the ROC clustering around 0.85 in recent studies. [Afdhal NH and Curry M, 2007].

\begin{tabular}{|c|c|c|c|c|c|c|c|c|c|c|}
\hline Author, year & $\begin{array}{l}\text { Patients } \\
\text { selection }\end{array}$ & Patients & Control & Calculation & $\begin{array}{l}\text { Fibrosis } \\
\text { stage }\end{array}$ & AUC & $\begin{array}{l}\text { Sensitivity } \\
{[\%]}\end{array}$ & $\begin{array}{l}\text { Specificity } \\
{[\%]}\end{array}$ & $\begin{array}{l}\text { PPV } \\
{[\%]}\end{array}$ & $\begin{array}{l}\text { NPV } \\
{[\%]}\end{array}$ \\
\hline $\begin{array}{l}\text { Friedrich- } \\
\text { Rust M, } 2007\end{array}$ & $\begin{array}{l}\text { viral } \\
\text { hepatitis }\end{array}$ & 79 & 20 & $\begin{array}{l}\text { elasticity score, } \\
\text { stepwise } \\
\text { multivariate } \\
\text { logistic regression }\end{array}$ & $\begin{array}{l}F=1 \\
F=4\end{array}$ & $\begin{array}{l}0.75 \\
0.69\end{array}$ & $\begin{array}{c}80 \\
29.2\end{array}$ & $\begin{array}{l}61.1 \\
90.7\end{array}$ & $\begin{array}{c}63.2 \\
50\end{array}$ & $\begin{array}{c}78.6 \\
80\end{array}$ \\
\hline $\begin{array}{l}\text { Friedrich- } \\
\text { Rust M, } 2009\end{array}$ & $\begin{array}{l}\text { chronic liver } \\
\text { disease }\end{array}$ & 134 & & $\begin{array}{l}\text { Japanese Elasticity } \\
\text { score, } 256 \text { stepwise } \\
\text { of color mapping }\end{array}$ & $\begin{array}{l}F=1 \\
F=4\end{array}$ & $\begin{array}{l}0.64 \\
0.63\end{array}$ & & & & \\
\hline $\begin{array}{l}\text { Kanamoto M, } \\
2009\end{array}$ & $\begin{array}{l}\text { underwent } \\
\text { an operation }\end{array}$ & 41 & & $\begin{array}{l}\text { Elastic ratio, ratio } \\
\text { of liver for the } \\
\text { intercostal muscle }\end{array}$ & $\begin{array}{l}F=1 \\
F=4\end{array}$ & & $\begin{array}{l}96.2 \\
93.3\end{array}$ & $\begin{array}{l}73.3 \\
73.1\end{array}$ & $\begin{array}{l}86.2 \\
66.7\end{array}$ & $\begin{array}{c}91.7 \\
95\end{array}$ \\
\hline Wang J, 2010 & $\begin{array}{l}\text { chronic } \\
\text { hepatitis B }\end{array}$ & 55 & 20 & $\begin{array}{l}\text { Elastic index, } \\
\text { principal } \\
\text { components } \\
\text { analysis }\end{array}$ & $\begin{array}{l}F=1 \\
F=4\end{array}$ & $\begin{array}{l}0.93 \\
0.66\end{array}$ & $\begin{array}{l}87.3 \\
71.4\end{array}$ & $\begin{array}{l}85 \\
80\end{array}$ & $\begin{array}{l}94.1 \\
93.8\end{array}$ & $\begin{array}{c}70.8 \\
40\end{array}$ \\
\hline $\begin{array}{l}\text { Koizumi Y, } \\
2011\end{array}$ & $\begin{array}{l}\text { chronic } \\
\text { hepatitis C }\end{array}$ & 70 & & $\begin{array}{l}\text { Elastic ratio, ratio } \\
\text { of liver for the } \\
\text { small hepatic vein }\end{array}$ & $\begin{array}{l}F=1 \\
F=4\end{array}$ & $\begin{array}{l}0.89 \\
0.95\end{array}$ & $\begin{array}{l}83.8 \\
90.9\end{array}$ & $\begin{array}{l}90.9 \\
91.5\end{array}$ & $\begin{array}{c}98 \\
83.3\end{array}$ & $\begin{array}{c}50 \\
95.6\end{array}$ \\
\hline Our report & $\begin{array}{l}\text { chronic } \\
\text { hepatitis C }\end{array}$ & 101 & 10 & Mean & $\begin{array}{l}F=1 \\
F=4\end{array}$ & $\begin{array}{l}0.89 \\
0.91\end{array}$ & $\begin{array}{l}84.1 \\
85.7\end{array}$ & $\begin{array}{l}82.7 \\
82.9\end{array}$ & $\begin{array}{l}80.4 \\
46.2 \\
\end{array}$ & $\begin{array}{c}86 \\
97.1\end{array}$ \\
\hline
\end{tabular}

Table 2. Diagnostic accuracy of real time tissue elastography in individual studies.

Standard US, CT, and MRI have long been used to survey liver morphology. These modalities are able to detect changes in the liver parenchyma when there is early cirrhosis and signs of portal hypertension. However, these methods are not useful to identify the presence of mild fibrosis. In this regard, elastography is sensitive for evaluating liver fibrosis based on the fact that, as the liver becomes progressively fibrotic, it becomes harder and less elastic. The technique based on US and MRI easily and noninvasively measures the relative values of liver stiffness. TE has been used most frequently worldwide and has established a role in clinical practice for detecting advanced fibrosis instead of liver biopsy. A pioneering report from Castera in 2005 showed that the AUC of TE was 0.84 for the diagnosis of F1 and 0.94 for the diagnosis of cirrhosis. Although MR elastography (MRE) was shown to be superior to APRI and TE for determining the stage of fibrosis in patients with underlying liver diseases [Huwart L, 2008], MRE cannot be performed on patients with an iron overloaded liver because of background noise. In addition, MRE takes more time and costs more than the US-based elastographies. 
Four published reports have compared the diagnostic accuracy of RTE with serum markers including APRI. RTE was shown to be superior to APRI in determining the stage of liver fibrosis in all of these studies except for the first report by Friedrich-Rust in 2007. It is believed that the more sensitive probes have been developed which could mitigate the deep attenuation of the ultrasound image and without requiring external stress. Accordingly, we were able to avoid the influence of the liver surface inside the ROI which is hard and therefore assessed as a harder area and to improve the acquisition of the color image representing the distortion of liver tissue due to the heartbeat or the pulse of the abdominal aorta without interobserver variability.

Although Friedrich-Rust (2009) reported that RTE was inferior in determining the stage of liver fibrosis compared to TE, our results presented in Table 1 indicated that the performance of RTE compares favorably with that of TE for detecting the degree of liver fibrosis in patients with chronic hepatitis $\mathrm{C}$. TE has been reported to have several limitations and disadvantages in evaluating patients with obesity and ascites. In fact, in our study, we achieved successful evaluation of all patients with RTE, while five patients (F1, 2; F3, 1; F4, 2) failed to receive TE measurements due to obesity and liver atrophy. Koizumi also reported that RTE could be employed in patients with BMIs greater than $30 \mathrm{~kg} / \mathrm{m}^{2}$.

Although the results from RTE were conducted by the image of color map, the results were calculated by either the ratio of strain distribution between ROI of the liver parenchyma and that of another area or by the image analysis of ROI. The method of Kanamoto which was used intercostal muscle as the reference for the ratio was inferior to the other method, since the area is considered to be influenced by instability of tissue distortion of subcutaneous fat and by the liver surface which is one of the hardest areas in liver parenchyma. In contrast, Koizumi adopted the hepatic vein as a reference and obtained the best sensitivity and specificity for characterizing the stage of fibrosis in related articles. Other studies utilized image analysis using exclusive software and reported different results. Thus the best method for the analysis and unit of RTE remains unclear, but may be revealed by future multicenter studies using larger patient cohorts.

In the future, the combination of image modalities with serological parameters will further improve the accuracy in differentiating fibrosis stages. Interestingly, Castera reported that the best results were achieved by a combination of TE with the FibroTest. Although acoustic radiation force impulse, which is a most recent technology, TE, and MRE are all based on shear wave propagation, RTE is constructed by an original theory which is based on tissue distortion. Friedrich-Rust reported in 2007 that the best diagnostic accuracy was obtained by combining the variables used for the calculation of the RTE elasticity score with the platelet count and GGT.

Elastography will be applicable to the screening of hepatocellular carcinoma (HCC) and the complication of cirrhosis. In the METAVIR and Desmet's histological scoring systems, cirrhosis is classified as a single category, F4. However, the degree of fibrosis that indicates the amount of extracellular matrix materials including collagen that may be closely associated with the function of hepatocytes and portal hypertension may vary among patients with cirrhosis. Foucher reported in 2006 that liver stiffness (kPa) measured by TE in cirrhotic patients correlates well with clinical parameters indicating the severity of cirrhosis; $27.5 \mathrm{kPa}$ was the cutoff value for the presence of esophageal varices stage 2 or $3,37.5 \mathrm{kPa}$ for liver function Child B or C, $49.1 \mathrm{kPa}$ for a past history of ascites, and $62.7 \mathrm{kPa}$ for bleeding from esophageal varices. Masuzaki prospectively observed that, in 866 patients with chronic hepatitis C, HCC developed in 77 cases within 3 years of observation, and $0.4 \%$ of HCC was 
detected in patients whose liver stiffness at entry was less than $10 \mathrm{kPa}$ and $38.5 \%$ of it was more than $25 \mathrm{kPa}$, indicating the usefulness of liver stiffness measurement as a tool for predicting the development of HCC. Because RTE is expected to stage cirrhosis in greater detail with clinical relevance, it may be useful for detecting and assessing the risk of cirrhotic complications and the development of HCC.

Although noninvasive assessment of liver fibrosis is already established in patients with chronic hepatitis $\mathrm{C}$, it is still necessary to improve assessment in other highly prevalent diseases, such as non-alcoholic fatty liver disease/non-alcoholic steatohepatitis (NASH). We reported that the AUC of AAR, age-platelet index, APRI, and cirrhosis discriminant score for predicting cirrhosis were $0.81,0.87,0.79$, and 0.95 , respectively, in 50 patients with NASH and $0.56,0.65,0.76$, and 0.78 , respectively, in 100 patients with chronic hepatitis C [Fujii H 2009]. RTE will be expected to play a major role in elastography for these patients, since it is not influenced by obesity or BMI.

\section{Conclusion}

We have described a convenient and noninvasive procedure, RTE, for the visual assessment of liver stiffness. The performance of RTE compared favorably to TE for detecting the degree of liver fibrosis in patients with chronic hepatitis C. We suggest that RTE could also be used as a routine imaging method to evaluate the degree of liver fibrosis in patients with liver diseases other than chronic hepatitis C. Future studies on larger patient cohorts will be necessary for the validation of RTE analysis, and the combination of RTE parameters with other clinical values including serum biomarkers will enable improvement of accuracy in assessing hepatic fibrosis.

\section{Acknowledgment}

We thank Ms. Akiko Tonomura and Mr. Junji Warabino, Hitachi Medical Co., for the technical support for RTE. Hiroyasu Morikawa was supported by a research grant from Osaka City University (2009). Norifumi Kawada was supported by Research on Hepatitis, Health and Labour Science Research Grants from the Ministry of Health, Labour and Welfare of Japan (2008-2009) and by a Thrust Area Research Grant from Osaka City University.(2008-2009).

\section{References}

Afdhal NH and Curry M (2007) Technology evaluation: a critical step in the clinical utilization of novel diagnostic tests for liver fibrosis. J Hepatol 46: 543-54

Castera L, Vergniol J, Foucher J, Le Bail B, Chanteloup E, Haaser M. (2005) Prospective comparison of transient elastography, Fibrotest, APRI, and liver biopsy for the assessment of fibrosis in chronic hepatitis C. Gastroenterology. 2005;128:343-50.

Forns X, Ampurdane`s S, Llovet JM, Aponte J, Quinto' L, Marti'nez-Bauer E, et al. Identification of chronic hepatitis $C$ patients without hepatic fibrosis by a simple predictive model. Hepatology. 2002;36:986-92.

Foucher J, Chanteloup E, Vergniol J, Caste'ra L, Le Bail B, Adhoute X. (2006) Diagnosis of cirrhosis by transient elastography (FibroScan): a prospective study. Gut. 2006;55:403-8 
Friedrich-Rust M, Ong MF, Herrmann E, Dries V, Samaras P, Zeuzem S, Sarrazin C. (2007) Real-time elastography for noninvasive assessment of liver fibrosis in chronic viral hepatitis. AJR Am J Roentgenol. 2007;188:758-64.

Friedrich-Rust M, Schwarz A, Ong M, Dries V, Schirmacher P, Herrmann E, Samaras P, Bojunga J, Bohle RM, Zeuzem S, Sarrazin C. (2009) Real-time tissue elastography versus FibroScan for noninvasive assessment of liver fibrosis in chronic liver disease. Ultraschall Med. $2009 ; 30: 478-84$.

Fujii H, Enomoto M, Fukushima W, Ohfuji S, Mori M, Kobayashi S, Iwai S, Morikawa H, Tamori A, Sakaguchi H, Ikura Y, Ueda M, Kawada N. (2009) Noninvasive laboratory tests proposed for predicting cirrhosis in patients with chronic hepatitis $\mathrm{C}$ are also useful in patients with non-alcoholic steatohepatitis. J Gastroenterol. 2009;44:608-14

Guha IN, Parkes J, Roderick P, et al. Noninvasive markers of fibrosis in nonalcoholic fatty liver disease: Validating the European Liver Fibrosis Panel and exploring simple markers. Hepatology. 2008;47:455-460.

Huwart L, Sempoux C, Vicaut E, Salameh N, Annet L, Danse E. (2008) Magnetic resonance elastography for the noninvasive staging of liver fibrosis. Gastroenterology. 2008;135:32-40

Imbert-Bismut F, Ratziu V, Pieroni L, Charlotte F, Benhamou Y, Poynard T, et al. Biochemical markers of liver fibrosis in patients with hepatitis $C$ virus infection: a prospective study. Lancet.2001;357:1069-75.

Kanamoto M, Shimada M, Ikegami T, Uchiyama H, Imura S, Morine Y, Kanemura H, Arakawa Y, Nii A. (2009) Real time elastography for noninvasive diagnosis of liver fibrosis. J Hepatobiliary Pancreat Surg. 2009;16(4):463-7.

Koizumi Y, Hirooka M, Kisaka Y, Konishi I, Abe M, Murakami H, Matsuura B, Hiasa Y, Onji M. (2011) Liver fibr osis in patients with chronic hepatitis C: noninvasive diagnosis by means of real-time tissue elastography--establishment of the method for measurement. Radiology. $2011 ; 258$ :610-7.

Masuzaki R, Tateishi R, Yoshida H, Goto E, Sato T, Ohki T, Imamura J, Goto T, Kanai F, Kato N, Ikeda H, Shiina S, Kawabe T, Omata M. (2009) Prospective risk assessment for hepatocellular carcinoma development in patients with chronic hepatitis $C$ by transient elastography. Hepatology. $2009 ; 49$ :1954-61.

Morikawa H, Fukuda K, Kobayashi S, Fujii H, Iwai S, Enomoto M, Tamori A, Sakaguchi H, Kawada N. (2010) Real-time tissue elastography as a tool for the noninvasive assessment of liver stiffness in patients with chronic hepatitis C. J Gastroenterol. 2010 Aug 10. [Epub ahead of print]

Ophir J, Céspedes I, Ponnekanti H, Yazdi Y, Li X. (1991) Elastography: a quantitative method for imaging the elasticity of biological tissues. Ultrason Imaging. 1991;13:111-34.

Shiina T, Nitta N, Ueno E, Bamber JC. (2002) Real time tissue elasticity imaging using the combined autocorrelation method. J Med Ultrason 2002;29:119-128.

Wai CT, Greenson JK, Fontana RJ, Kalbfleisch JD, Marrero JA, Conjeevaram HS, et al. A simple noninvasive index can predict both significant fibrosis and cirrhosis in patients with chronic hepatitis C. Hepatology. 2003;38:518-26.

Wang J, Guo L, Shi X, Pan W, Bai Y, Ai H. (2011) Real-time elastography with a novel quantitative technology for assessment of liver fibrosis in chronic hepatitis B. Eur J Radiol. 2011 Jan 6. [Epub ahead of print]

Yeh WC, Li PC, Jeng YM, Hsu HC, Kuo PL, Li ML. (2002) Elastic modulus measurements of human liver and correlation with pathology. Ultrasound Med Biol. 2002; 28 : 467-74. 


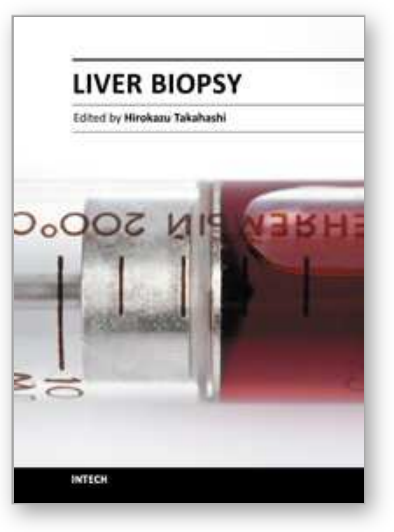

\author{
Liver Biopsy \\ Edited by Dr Hirokazu Takahashi
}

ISBN 978-953-307-644-7

Hard cover, 404 pages

Publisher InTech

Published online 06, September, 2011

Published in print edition September, 2011

Liver biopsy is recommended as the gold standard method to determine diagnosis, fibrosis staging, prognosis and therapeutic indications in patients with chronic liver disease. However, liver biopsy is an invasive procedure with a risk of complications which can be serious. This book provides the management of the complications in liver biopsy. Additionally, this book provides also the references for the new technology of liver biopsy including the non-invasive elastography, imaging methods and blood panels which could be the alternatives to liver biopsy. The non-invasive methods, especially the elastography, which is the new procedure in hot topics, which were frequently reported in these years. In this book, the professionals of elastography show the mechanism, availability and how to use this technology in a clinical field of elastography. The comprehension of elastography could be a great help for better dealing and for understanding of liver biopsy.

\title{
How to reference
}

In order to correctly reference this scholarly work, feel free to copy and paste the following:

Hiroyasu Morikawa and Norifumi Kawada (2011). The Current Status of Non-Invasive Assessment of Liver Fibrosis: Real Time Tissue Elastography, Liver Biopsy, Dr Hirokazu Takahashi (Ed.), ISBN: 978-953-307-6447, InTech, Available from: http://www.intechopen.com/books/liver-biopsy/the-current-status-of-non-invasiveassessment-of-liver-fibrosis-real-time-tissue-elastography

\section{INTECH}

open science | open minds

\section{InTech Europe}

University Campus STeP Ri

Slavka Krautzeka 83/A

51000 Rijeka, Croatia

Phone: +385 (51) 770447

Fax: +385 (51) 686166

www.intechopen.com

\section{InTech China}

Unit 405, Office Block, Hotel Equatorial Shanghai

No.65, Yan An Road (West), Shanghai, 200040, China

中国上海市延安西路65号上海国际贵都大饭店办公楼 405 单元

Phone: +86-21-62489820

Fax: $+86-21-62489821$ 
(C) 2011 The Author(s). Licensee IntechOpen. This chapter is distributed under the terms of the Creative Commons Attribution-NonCommercialShareAlike-3.0 License, which permits use, distribution and reproduction for non-commercial purposes, provided the original is properly cited and derivative works building on this content are distributed under the same license. 